\title{
Impact of Nutritional Indices on the Survival Outcomes of Patients with Colorectal Cancer
}

This article was published in the following Dove Press journal:

Cancer Management and Research

\author{
Zhengyu $\mathrm{Hu}^{\mathrm{l}}$ ** \\ Yan $\mathrm{Li}^{2}$,* \\ Weipu $\mathrm{Mao}^{3}$ \\ Bo Chen' \\ Lin Yang ${ }^{2}$ \\ Xiangling Meng' \\ 'Department of Gastrointestinal Surgery, \\ The First Affiliated Hospital of Anhui \\ Medical University, Hefei, Anhui Province \\ 230032, People's Republic of China; \\ ${ }^{2}$ Department of Radiation Oncology, The \\ First Affiliated Hospital of Anhui Medical \\ University, Hefei, Anhui Province 230032, \\ People's Republic of China; ${ }^{3}$ Department \\ of Urology, Shanghai Tenth People's \\ Hospital, School of Medicine, Tongii \\ University, Shanghai 200072, People's \\ Republic of China \\ *These authors contributed equally to \\ this work
}

Background: The effect of preoperative nutritional status on the survival of patients with colorectal cancer is still unknown. The purpose of our study was to examine the impact of the prognostic nutritional index (PNI), prealbumin (PAB) and the albumin to globulin ratio (AGR) on survival outcomes in patients with colon and rectal cancer.

Methods: Between January 2012 and December 2013, 361 patients with colorectal cancer who underwent curative surgery in the survey and various clinical and haematological parameters were recorded. The optimal cut-off values of the PNI, PAB and AGR were determined by MedCalc software, and Cox regression analysis was performed to investigate the effect of the PNI, PAB and AGR on the overall survival (OS) of patients with colon and rectal cancer. Results: In patients with colon and rectal cancer, a high PNI, PAB, and AGR correlate with higher survival times. Receiver operating characteristic (ROC) curve analysis showed that at most time points, the PNI has a higher area under the curve (AUC) in predicting colon and rectal cancer OS. Multivariate Cox regression analysis showed that of the PNI, PAB and AGR, only the PNI was an independent risk factor for OS in patients with colon and rectal cancer. Patients with a high PNI were predicted to have higher OS (hazard ratio [HR]: $0.479 ; 95 \%$ confidence interval $[\mathrm{CI}]: 0.233-0.985 ; \mathrm{P}=0.045)$ in colon cancer and higher OS (HR: 0.225; 95\% CI: 0.111-0.454; $\mathrm{P}<0.001$ ) in rectal cancer compared with patients with a low PNI.

Conclusion: Preoperative PNI, PAB and AGR may be predictors of OS in patients with colon and rectal cancer after radical surgery, especially the PNI, which has a good ability to predict OS in both tumours.

Keywords: PNI, PAB, AGR, colon cancer, rectal cancer, overall survival

\section{Introduction}

Colorectal cancer, including colon and rectal cancer, is the most common malignant tumour in the digestive system, accounting for approximately half of digestive system tumours. ${ }^{1}$ In 2019, an estimated 101,420 new colon cancer cases, 44,180 new rectal cancer cases and 51,020 deaths from colorectal cancer were diagnosed in the United States. ${ }^{2}$ Colorectal cancer is the third leading cause of morbidity and mortality in both men and women. ${ }^{3}$ With the improvement in living standards and changes in diet, the incidence of colorectal cancer continues to rise. ${ }^{4}$ The treatment of colorectal cancer includes surgery, chemotherapy, radiotherapy and other biological immunological treatments. ${ }^{5}$ Surgical treatment is the first choice for the treatment of colorectal cancer. Due to its high invasion and metastasis, the 5-year survival rate is only approximately $50 \%{ }^{6}$

Due to the physiological colorectal functions, patients with colorectal cancer are prone to malnutrition. Malnutrition is a common problem for patients with cancer, with up to
Correspondence: Xiangling Meng

Tel +86-55I-62922035

Fax +86-55I-62922049

Email ayfy105080@163.com

Lin Yang

Tel/Fax +86-55I-62923545

Email Yanglin_ah@163.com 
$80 \%$ of patients with advanced cancer suffering from malnutrition. ${ }^{7}$ Although the basic mechanism of nutritional changes in cancer is not fully understood, the catabolic factors produced by cancer cells and the proinflammatory response of the host can induce energy consumption, resulting in weight loss and eventual malnutrition. ${ }^{8}$ It is of great significance to find an accurate and effective index before surgery to evaluate the nutritional status and surgical risk of patients and to determine the clinical outcome of patients after surgery.

At present, the prognostic nutritional index (PNI), prealbumin (PAB) and albumin to globulin ratio (AGR) are widely studied and have been used as new parameters for many kinds of malignant tumours, including gastric cancer and pancreatic cancer. ${ }^{9-11}$ However, there is still a lack of research on nutritional indicators for colon and rectal cancer. Our study analysed the relationship between the above three indicators and the prognosis of patients with colon and rectal cancer to explore which indicator has better predictive value.

\section{Materials and Methods}

\section{Patients}

From January 2012 to December 2013, 403 patients with colorectal cancer who underwent curative surgery were invited to participate in general surgery research at the First Affiliated Hospital of Anhui Medical University. All patients were diagnosed with colorectal cancer according to the 7 th edition of the International Union Against Cancer (UICC) TNM Classification of Malignant Tumors. ${ }^{12}$ The study was approved by the Ethics Committee of the First Affiliated Hospital of Anhui Medical University. The patients understood the purpose of the study and signed an informed consent form.

Inclusion criteria: (a) colonoscopy and pathological examination confirmed the diagnosis of colorectal cancer; (b) patients who underwent curative surgery; and (c) older than 18 years.

Exclusion criteria: (a) preoperative neoadjuvant radiotherapy and chemotherapy; (b) multiple primary tumours; and (c) only gastrointestinal bypass surgery. The following patients were excluded: lost to follow-up data $(n=5)$; received targeted therapy $(\mathrm{n}=17)$; received chemotherapy $(n=18)$; and mental abnormalities $(n=2)$. Preoperative neoadjuvant treatment was performed for those patients who had preoperative MRI invasion of the parenteral tissue or lymph node metastases or tumours too large to resect and were not included in this study.

Based on the above exclusion and inclusion criteria, 361 patients participated in the study, including 180 patients with colon cancer and 181 patients with rectal cancer. Subsequent radiotherapy or chemotherapy was based on the 7th NCCN guideline unless the physical conditions would cause intolerance. The most common method of follow-up is a routine clinic visit supplemented by email and phone interviews. Overall survival (OS) was recorded as the time from the date of surgery to death or last follow-up. The study's endpoint was follow-up to December 31,2018 , or death.

\section{Data Collection}

The clinical data of the patients were collected, including age, sex, tumour size, tumour morphological type, tumour deposits, and TNM stage. Laboratory data such as lymphocytes, prealbumin, serum albumin and globulin were collected. All laboratory data were obtained within 1 week before surgery. The PNI was calculated using the formula: $10 \times$ albumin $(\mathrm{g} / \mathrm{dl})+0.005 \times$ lymphocyte $\left(/ \mathrm{mm}^{3}\right)$. The AGR was calculated as the albumin to globulin ratio.

\section{Statistical Analysis}

Continuous variables are described as averages, and classification variables are described as frequencies (percentages). MedCalc (MedCalc Software Ltd, Shen Zhen, China) version 15.2.0 software was used to calculate the optimal cut-off value of the PNI, PAB and AGR. ${ }^{13}$ The baseline characteristics between groups were compared using independent sample t-tests and chi-square tests as appropriate. Overall survival (OS) curves were drawn by the Kaplan-Meier method and evaluated using the log-rank test. The relationship between OS and potential confounding variables (including age, sex, tumour size, morphological type, tumour deposits, TNM stage, PNI, PAB and AGR) was determined by a Cox proportional risk regression model. MedCalc software was used to draw receiver operating characteristic (ROC) curves. The area under the curve (AUC) is the size of the area below the ROC curve. The area value of the AUC is between 1.0 and 0.5 . In the case of AUC $>0.5$, the closer to 1.0, the better the diagnostic effect is. $\mathrm{P}<0.05$ was considered statistically significant. Statistical analyses were performed by SPSS version 24.0 software (IBM Corporation, Somers, NY, USA).

\section{Results}

\section{Patient Characteristics}

According to the screening criteria in Figure 1, a total of 361 patients with colorectal cancer participated in the study from January 1, 2012, to December 31, 2013, including 180 


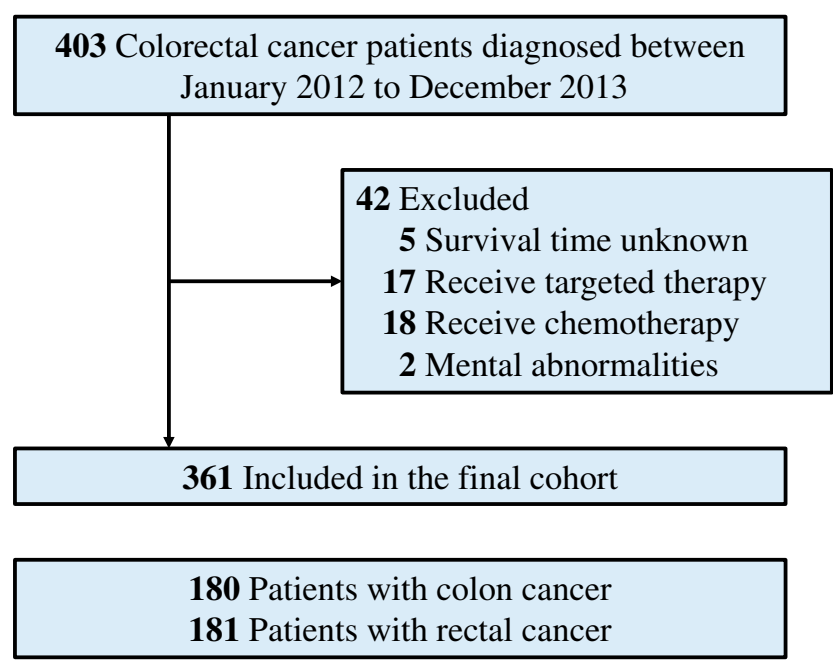

Figure I Schematic flow diagram of inclusion and exclusion criteria for our study cohort.

patients with colon cancer and 181 patients with rectal cancer. The baseline characteristics of the patients are shown in Table 1. In this study, the median age of patients with colon cancer was 63 years (average age $61.0 \pm 14.3$ ), and the median age of patients with rectal cancer was 61 years (average age $60.1 \pm 14.6$ ). Regardless of colon or rectal cancer, the following were the most common among patients: male $(57.8 \%, 63.5 \%)$, tumour size $\leq 5 \mathrm{~cm}(63.3 \%$, $85.6 \%)$, ulcerated morphological type $(66.7 \%, 61.9 \%)$, negative tumour deposits $(84.4 \%, 77.9 \%)$, stage I/II $(62.2 \%, 52.5 \%)$, and $\mathrm{PAB}>170 \mathrm{mg} / \mathrm{L}(71.1 \%, 86.7 \%)$.

\section{Survival Outcome}

As shown in Table 2, we used Kaplan-Meier curves and the log-rank test to evaluate factors associated with OS in colorectal cancer. We found that tumour deposits, TNM stage, PAB, PNI, and AGR were all factors associated with colon and rectal cancer (Figures 2 and 3). In both colon cancer and rectal cancer, compared with a low PAB, low PNI and low AGR, a high PAB (colon cancer: 72.5 (68.2-76.8) months; rectal cancer: 63.8 (59.5-68.2) months), high PNI (colon cancer: 72.5 (68.2-76.8) months); rectal cancer: 63.8 (59.5 -68.2) months) and high AGR (colon cancer: 72.5 (68.2-76.8) months; rectum cancer: 63.8 (59.5-68.2) months) indicated higher survival times.

\section{Factors Predicting the OS of Patients with Colon Cancer}

Univariate and multivariate Cox regression were used to analyse the factors associated with OS in patients with
Table I Clinicopathological Characteristics of Patients with Colon and Rectal Cancer

\begin{tabular}{|c|c|c|}
\hline \multirow[t]{2}{*}{ Characteristic } & Colon Cancer & Rectal Cancer \\
\hline & $n=180(\%)$ & $n=|8|(\%)$ \\
\hline $\begin{array}{l}\text { Age } \\
\qquad 600 y \\
>60 y\end{array}$ & $\begin{array}{l}63.0(61.0 \pm 14.3) \\
86(47.8) \\
94(52.2)\end{array}$ & $\begin{array}{l}61.0(60.1 \pm 14.6) \\
87(48.1) \\
94(51.9)\end{array}$ \\
\hline $\begin{array}{c}\text { Gender } \\
\text { Male } \\
\text { Female }\end{array}$ & $\begin{array}{l}104(57.8) \\
76(42.2)\end{array}$ & $\begin{array}{l}115(63.5) \\
66(36.5)\end{array}$ \\
\hline $\begin{array}{l}\text { Tumor Size } \\
\qquad 5 \mathrm{~cm} \\
>5 \mathrm{~cm}\end{array}$ & $\begin{array}{l}\text { II } 4(63.3) \\
66(36.7)\end{array}$ & $\begin{array}{l}\text { I55 (85.6) } \\
26(14.4)\end{array}$ \\
\hline $\begin{array}{l}\text { Morphological type } \\
\text { Elevated } \\
\text { Ulcerated } \\
\text { Infiltrated }\end{array}$ & $\begin{array}{l}42(23.3) \\
120(66.7) \\
18(10.0)\end{array}$ & $\begin{array}{l}54(29.8) \\
112(61.9) \\
15(8.3)\end{array}$ \\
\hline $\begin{array}{l}\text { Tumor deposits } \\
\text { Negative } \\
\text { Positive }\end{array}$ & $\begin{array}{l}152(84.4) \\
28(15.6)\end{array}$ & $\begin{array}{l}|4|(77.9) \\
40(22.1)\end{array}$ \\
\hline $\begin{array}{l}\text { TNM stage } \\
\text { I/II } \\
\text { III/IV }\end{array}$ & $\begin{array}{l}112(62.2) \\
68(37.8)\end{array}$ & $\begin{array}{l}95(52.5) \\
86(47.5)\end{array}$ \\
\hline $\begin{array}{l}\text { PAB } \\
\quad \leq 170 \mathrm{mg} / \mathrm{L} \\
>170 \mathrm{mg} / \mathrm{L}\end{array}$ & $\begin{array}{l}52(28.9) \\
I 28(7 \mid . I)\end{array}$ & $\begin{array}{l}24(13.3) \\
157(86.7)\end{array}$ \\
\hline $\begin{array}{l}\text { PNI } \\
\text { Low } \\
\text { High }\end{array}$ & $\begin{array}{l}92(51.1) \\
88(48.9)\end{array}$ & $\begin{array}{l}10(5.5) \\
17 \mid(94.5)\end{array}$ \\
\hline $\begin{array}{l}\text { AGR } \\
\text { Low } \\
\text { High }\end{array}$ & $\begin{array}{l}60(33.3) \\
120(66.7)\end{array}$ & $\begin{array}{l}104(57.5) \\
77(42.5)\end{array}$ \\
\hline
\end{tabular}

Notes: In colon cancer, the cut off values of PNI and AGR are 48.225 and I.325, respectively. In rectal cancer, the cut off values of PNI and AGR are 39.625 and 1.615 , respectively.

Abbreviations: PAB, Prealbumin; PNI, Prognostic nutritional index; AGR, Albumin to globulin ratio; TNM, T, Tumor (Topography), N, Lymph Node, M, Metastasis.

colorectal cancer. In Table 3, univariate analysis showed that tumour size, morphological type, TNM stage, PAB, PNI, and AGR were factors related to OS in patients with colon cancer. However, multivariate Cox analysis showed that only morphological type, TNM stage, PNI, and AGR were factors associated with colon cancer OS. Patients with a high PNI (vs low PNI; HR $=0.479,95 \% \mathrm{CI}$ $0.233-0.985, \mathrm{P}=0.045$ ) and high AGR (vs low AGR; $\mathrm{HR}=0.230,95 \%$ CI $0.121-0.435, \mathrm{P}<0.001)$ had lower risk. 
Table 2 Clinicopathological Characteristics of Colon and Rectal Cancer Associated with OS

\begin{tabular}{|c|c|c|c|c|}
\hline \multirow[t]{2}{*}{ Characteristic } & \multicolumn{2}{|l|}{ Colon Cancer } & \multicolumn{2}{|l|}{ Rectal Cancer } \\
\hline & $\begin{array}{l}\text { OS (Months) } \\
\text { [Mean }(95 \% \mathrm{Cl})]\end{array}$ & $P$ value & $\begin{array}{l}\text { OS (Months) } \\
\text { [Mean }(95 \% \mathrm{Cl})]\end{array}$ & $P$ value \\
\hline $\begin{array}{l}\text { Age } \\
\qquad \begin{array}{l}\leq 0 \mathrm{y} \\
>60 \mathrm{y}\end{array}\end{array}$ & $\begin{array}{l}71.9(66.6-77.2) \\
63.9(58.2-69.7)\end{array}$ & 0.067 & $\begin{array}{l}63.9(57.8-70.0) \\
60.4(54.6-66.1)\end{array}$ & 0.323 \\
\hline $\begin{array}{l}\text { Gender } \\
\text { Male } \\
\text { Female }\end{array}$ & $\begin{array}{l}69.1(64.0-74.1) \\
65.8(59.5-72.1)\end{array}$ & 0.337 & $\begin{array}{l}64.3(59.6-69.0) \\
58.3(50.3-66.3)\end{array}$ & 0.814 \\
\hline $\begin{array}{l}\text { Tumor Size } \\
\qquad 5 \mathrm{~cm} \\
>5 \mathrm{~cm}\end{array}$ & $\begin{array}{l}70.6(66.1-75.2) \\
62.8(55.5-70.0)\end{array}$ & 0.015 & $\begin{array}{l}61.9(57.3-66.5) \\
62.7(53.2-72.3)\end{array}$ & 0.645 \\
\hline $\begin{array}{l}\text { Morphological type } \\
\text { Elevated } \\
\text { Ulcerated } \\
\text { Infiltrated }\end{array}$ & $\begin{array}{l}66.0(57.6-74.4) \\
68.5(63.8-73.2) \\
59.7(47.3-72.1)\end{array}$ & 0.881 & $\begin{array}{l}67.6(61.1-74.1) \\
60.6(54.9-66.2) \\
49.2(39.2-59.2)\end{array}$ & 0.059 \\
\hline $\begin{array}{l}\text { Tumor deposits } \\
\text { Negative } \\
\text { Positive }\end{array}$ & $\begin{array}{l}70.2(66.2-74.3) \\
53.5(42.1-64.9)\end{array}$ & 0.002 & $\begin{array}{l}65.2(60.6-69.8) \\
51.3(42.3-60.2)\end{array}$ & 0.001 \\
\hline $\begin{array}{l}\text { TNM stage } \\
\text { I/II } \\
\text { III/IV }\end{array}$ & $\begin{array}{l}77.1(73.6-80.5) \\
52.5(45.1-60.0)\end{array}$ & $<0.0001$ & $\begin{array}{l}71.2(66.6-75.9) \\
50.8(44.5-57.1)\end{array}$ & $<0.0001$ \\
\hline $\begin{array}{l}\text { PAB } \\
\quad \leq 170 \mathrm{mg} / \mathrm{L} \\
>170 \mathrm{mg} / \mathrm{L}\end{array}$ & $\begin{array}{l}56.0(48.1-63.9) \\
72.5(68.2-76.8)\end{array}$ & $<0.0001$ & $\begin{array}{l}49.9(37.2-62.6) \\
63.8(59.5-68.2)\end{array}$ & 0.031 \\
\hline $\begin{array}{l}\text { PNI } \\
\text { Low } \\
\text { High }\end{array}$ & $\begin{array}{l}59.3(52.9-65.7) \\
76.8(73.0-80.6)\end{array}$ & $<0.0001$ & $\begin{array}{l}21.8(7.3-36.3) \\
64.5(60.4-68.5)\end{array}$ & $<0.0001$ \\
\hline $\begin{array}{l}\text { AGR } \\
\text { Low } \\
\text { High }\end{array}$ & $\begin{array}{l}52.7(45.0-60.4) \\
74.6(70.8-78.5)\end{array}$ & $<0.0001$ & $\begin{array}{l}58.5(53.0-64.0) \\
66.4(60.1-72.6)\end{array}$ & 0.038 \\
\hline
\end{tabular}

Notes: P-value $<0.05$ are shown in bold. In colon cancer, the cut off values of PNI and AGR are 48.225 and I.325, respectively. In rectal cancer, the cut off values of PNI and AGR are 39.625 and 1.615 , respectively.

Abbreviations: PAB, Prealbumin; PNI, Prognostic nutritional index; AGR, Albumin to globulin ratio; TNM, T, Tumor (Topography), N, Lymph Node, M,

Metastasis; OS, overall survival; $\mathrm{Cl}$, confidence interval.

In Table 4, univariate analysis showed that morphological type, TNM stage, PAB, PNI, and AGR were factors associated with the OS of patients with rectal cancer. After adjusting for the above factors, multivariate Cox analysis showed that only TNM stage and PNI were independent prognostic risk factors for the OS of patients with rectal cancer. Cox regression showed that patients with a high PNI (HR $=0.225,95 \%$ CI $0.111-$ $0.454, \mathrm{p}<0.001$ ) had higher OS than patients with a low PNI.
Time-Dependent ROC Analysis for the PNI, PAB and AGR in Colon Cancer and Rectal Cancer

In the ROC analysis, the AUC of the PNI was greater than that of the PAB and AGR used to predict OS (AUC: 0.709; 95\% [CI]: 0.636-0.774; $\mathrm{P}<0.001)$ in patients with colon cancer at most time points. In addition, the PNI still had a high AUC to predict OS (AUC: 0.571; 95\% [CI]: $0.496-0.645 ; \mathrm{P}=0.641)$ in patients with rectal cancer (Figure 4 and Table 5). 
A

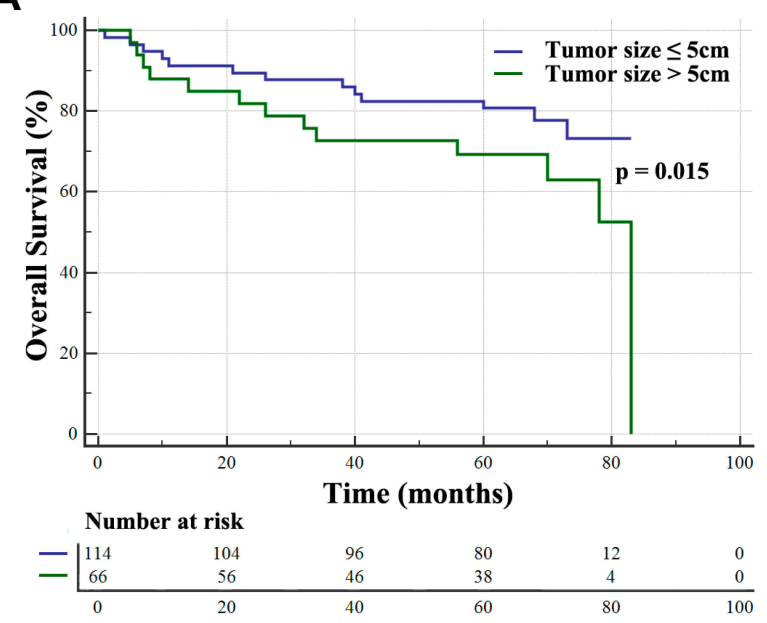

C

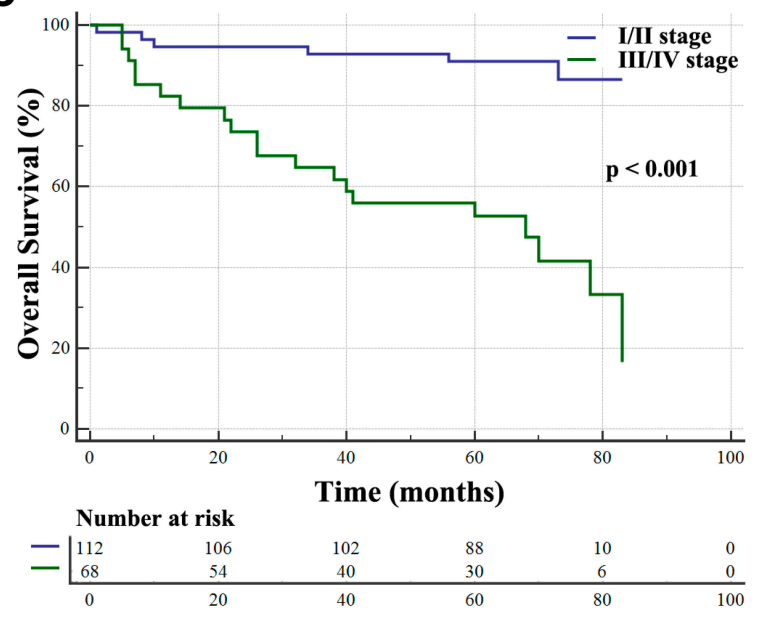

E

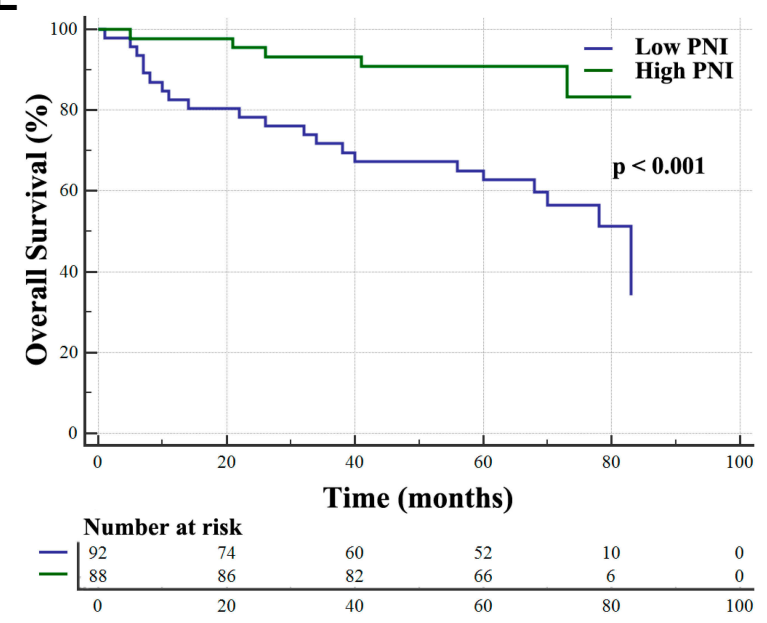

B

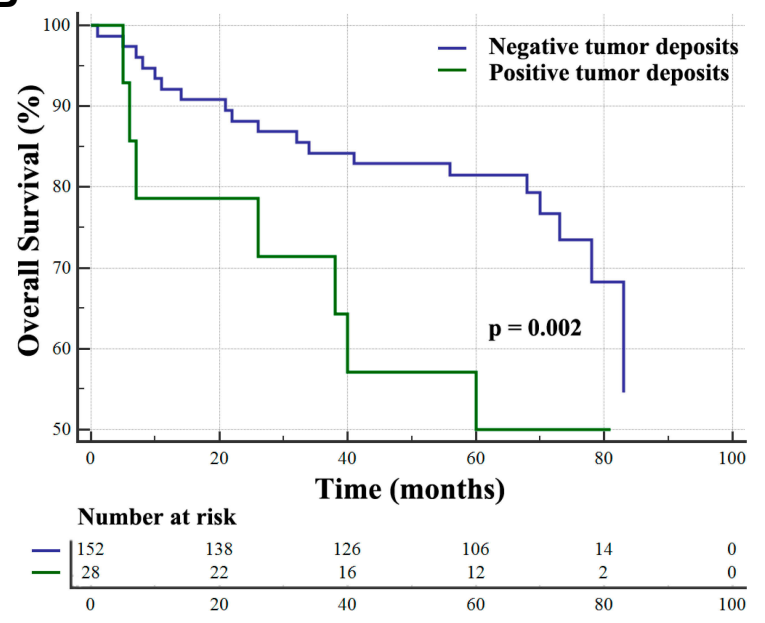

D
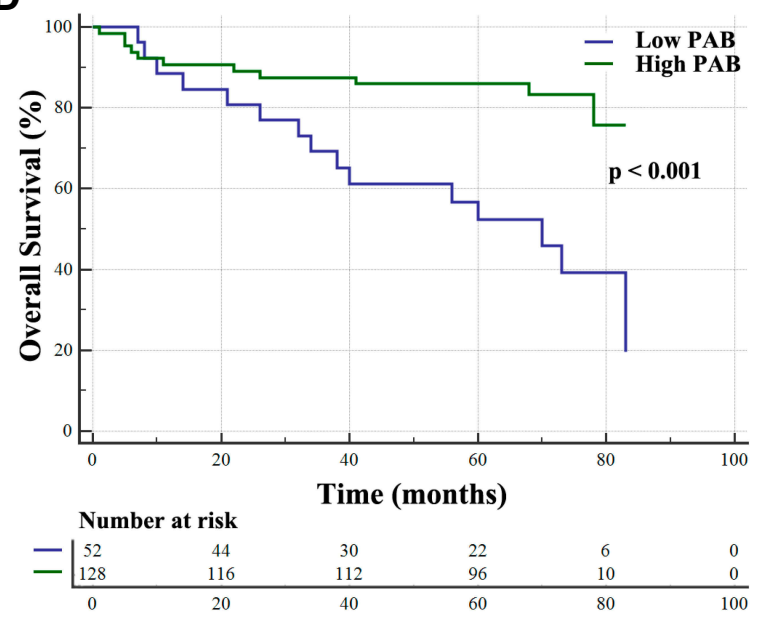

F
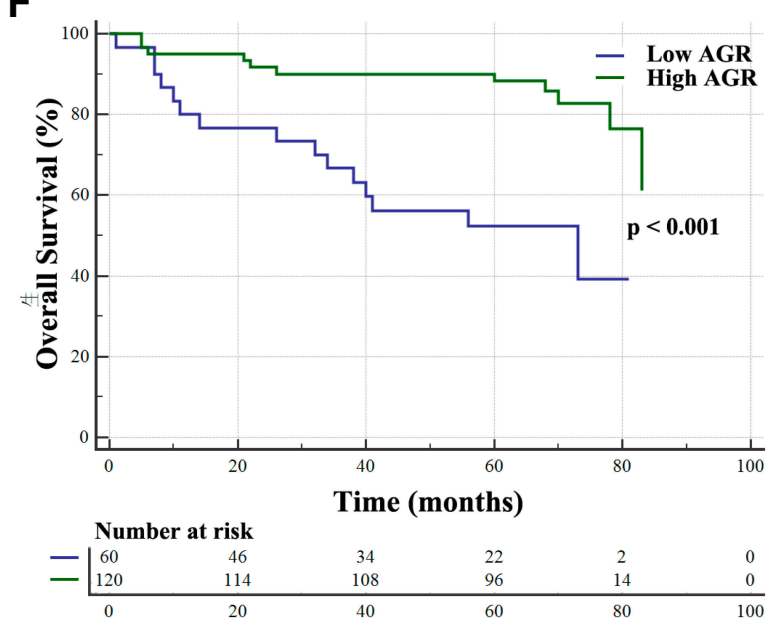

Figure 2 Kaplan-Meier survival curves of different variables in patients with colon cancer. (A) Tumor size; (B) Tumor deposits; (C) TNM stage; (D) Prealbumin (PAB); (E) Prognostic nutritional index (PNI); (F) Albumin and globulin ratio (AGR).

Abbreviations: TNM stage, T, Tumor (Topography), N, Lymph Node, M, Metastasis. 
A

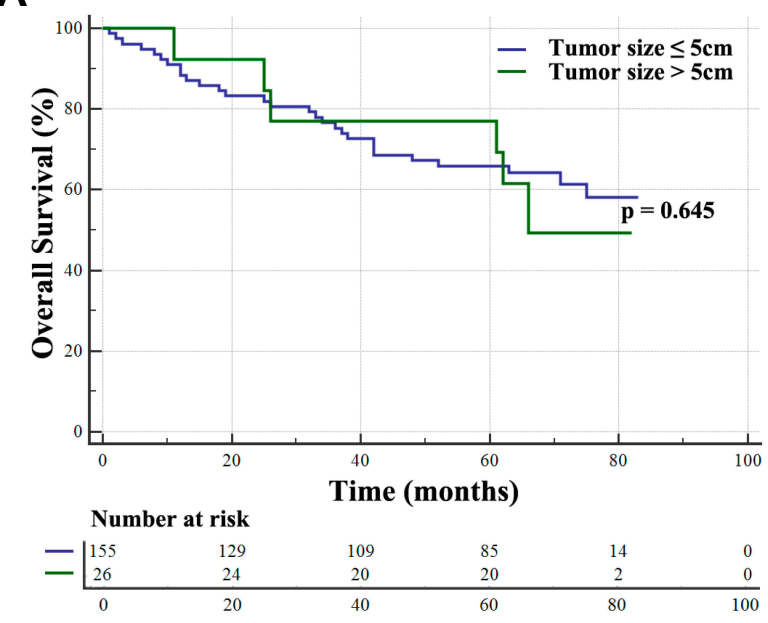

C

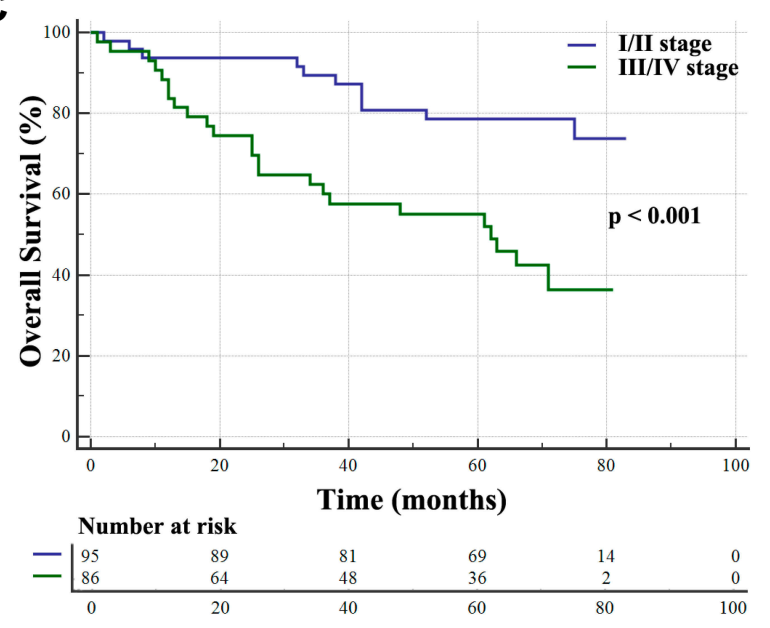

E
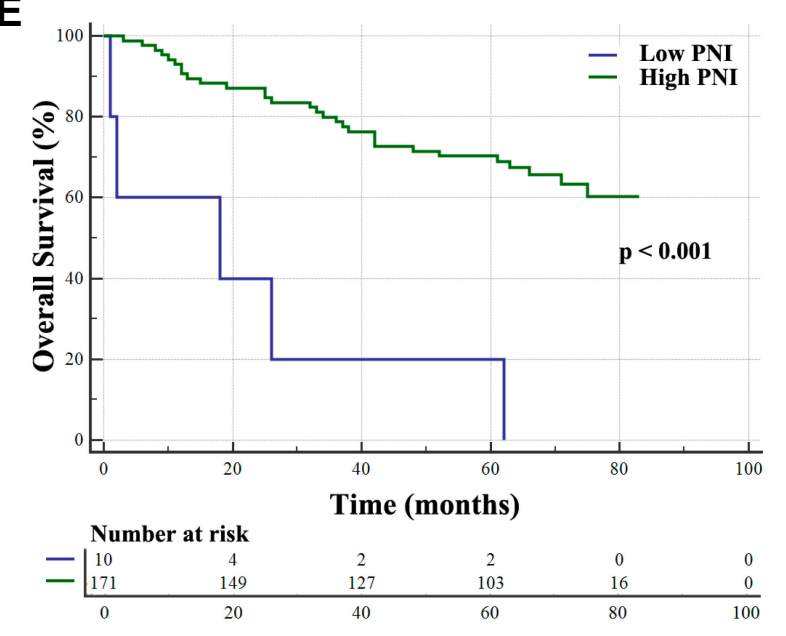

B
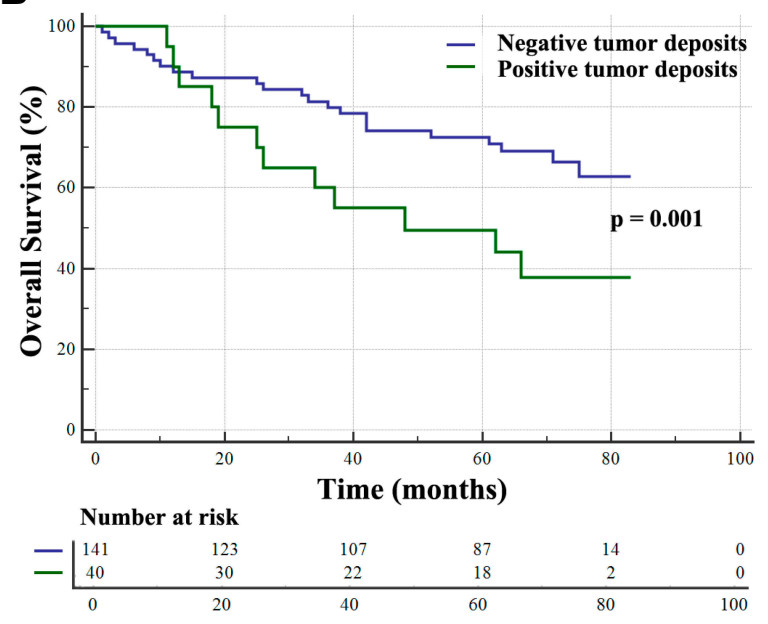

D
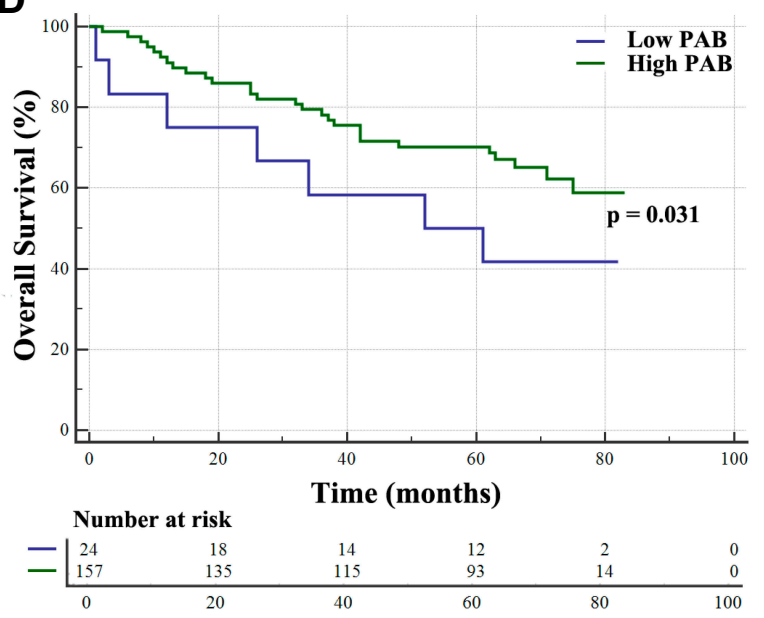

$\mathbf{F}$
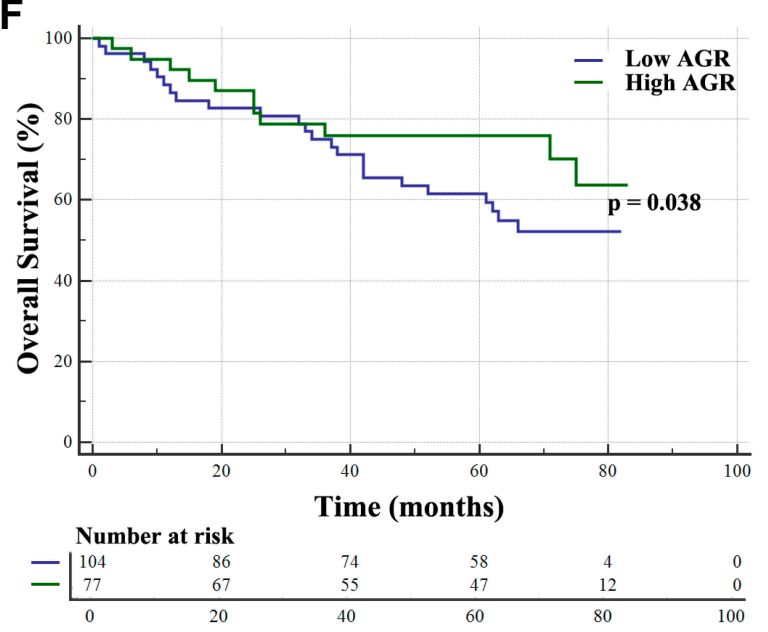

Figure 3 Kaplan-Meier survival curves of different variables in patients with rectal cancer. (A) Tumor size; (B) Tumor deposits; (C) TNM stage; (D) Prealbumin (PAB); (E) Prognostic nutritional index (PNI); (F) Albumin and globulin ratio (AGR).

Abbreviations: TNM stage, T, Tumor (Topography), N, Lymph Node, M, Metastasis. 
Table 3 Univariate and Multivariate Analysis of Prognostic Factors for Overall Survival (OS) of Colon Cancer Patients

\begin{tabular}{|c|c|c|c|c|}
\hline \multirow[t]{2}{*}{ Characteristic } & \multicolumn{2}{|l|}{ Univariate Analysis } & \multicolumn{2}{|l|}{ Multivariate Analysis } \\
\hline & $\begin{array}{l}\text { Hazard Ratio } \\
{[95 \% \mathrm{Cl}]}\end{array}$ & $P$ value & $\begin{array}{l}\text { Hazard Ratio } \\
{[95 \% \mathrm{Cl}]}\end{array}$ & $P$ value \\
\hline $\begin{array}{l}\text { Age } \\
\qquad 60 y \\
>60 y\end{array}$ & $\begin{array}{l}\text { I } \\
1.691[0.951-3.000]\end{array}$ & 0.072 & & \\
\hline $\begin{array}{c}\text { Gender } \\
\text { Male } \\
\text { Female }\end{array}$ & $\begin{array}{l}\mathrm{I} \\
\mathrm{I} .303[0.755-2.247]\end{array}$ & 0.342 & & \\
\hline $\begin{array}{l}\text { Tumor Size } \\
\qquad 5 \mathrm{~cm} \\
>5 \mathrm{~cm}\end{array}$ & $\begin{array}{l}\text { I } \\
1.933[1.120-3.335]\end{array}$ & 0.018 & $\begin{array}{l}\text { I } \\
-\end{array}$ & 0.985 \\
\hline $\begin{array}{l}\text { Morphological ty } \\
\text { Elevated } \\
\text { Ulcerated } \\
\text { Infiltrated }\end{array}$ & $\begin{array}{l}\text { I } \\
\mathrm{I} .165[0.60 \mathrm{I}-2.259] \\
\mathrm{I} .008[0.32 \mathrm{I}-3.169]\end{array}$ & $\begin{array}{l}0.651 \\
0.989\end{array}$ & & \\
\hline $\begin{array}{l}\text { Tumor deposits } \\
\text { Negative } \\
\text { Positive }\end{array}$ & $\begin{array}{l}\text { I } \\
2.575[1.387-4.780]\end{array}$ & 0.003 & $\begin{array}{l}\text { I } \\
0.472[0.234-0.954]\end{array}$ & 0.037 \\
\hline $\begin{array}{l}\text { TNM stage } \\
\text { I/II } \\
\text { III/IV }\end{array}$ & $\begin{array}{l}\text { I } \\
7.137[3.734-13.639]\end{array}$ & $<0.0001$ & $9.002[4.372-18.536]$ & $<0.000$ I \\
\hline $\begin{array}{l}\text { PAB } \\
\quad \leq 170 \mathrm{mg} / \mathrm{L} \\
>170 \mathrm{mg} / \mathrm{L}\end{array}$ & $\begin{array}{l}\text { I } \\
0.267[0.154-0.465]\end{array}$ & $<0.0001$ & $\begin{array}{l}1 \\
-\end{array}$ & 0.482 \\
\hline $\begin{array}{l}\text { PNI } \\
\text { Low } \\
\text { High }\end{array}$ & $\begin{array}{l}\text { I } \\
0.226[0.113-0.452]\end{array}$ & $<0.0001$ & $\begin{array}{l}\text { I } \\
0.479[0.233-0.985]\end{array}$ & 0.045 \\
\hline $\begin{array}{l}\text { AGR } \\
\text { Low } \\
\text { High }\end{array}$ & $\begin{array}{l}\text { I } \\
0.241[0.136-0.428]\end{array}$ & $<0.0001$ & $\begin{array}{l}\text { I } \\
0.230[0.121-0.435]\end{array}$ & $<0.0001$ \\
\hline
\end{tabular}

Notes: P-value $<0.05$ are shown in bold. In colon cancer, the cut off values of PNI and AGR are 48.225 and I.325, respectively. In rectal cancer, the cut off values of PNI and AGR are 39.625 and 1.615 , respectively.

Abbreviations: PAB, Prealbumin; PNI, Prognostic nutritional index; AGR, Albumin to globulin ratio; TNM, T, Tumor (Topography), N, Lymph Node, M, Metastasis; OS, overall survival; $\mathrm{Cl}$, confidence interval.

\section{Relationship Between the TNM Stage and} $\mathrm{PNI}, \mathrm{PAB}$ and $\mathrm{AGR}$ in Patients with Colon

\section{Cancer and Rectal Cancer}

The chi-square test was used to detect the correlation between TNM stage and PAB, PNI and AGR in colon and rectal cancer. The results showed that the PNI was related to the TNM stage of patients with colon cancer, and PAB and the PNI were related to the TNM stage of patients with rectal cancer. Among patients with colon cancer, the number of patients with a low PNI in stage III/IV was significantly higher than that with a high PNI $\left(\chi^{2}=8.083, \mathrm{P}=0.004\right)$ (Table S1). In rectal cancer, although the number of patients in the low PAB and low PNI groups was small, the number of patients with stage III/IV disease in the low $\mathrm{PAB}\left(\chi^{2}=8.382\right.$, $\mathrm{P}=0.004)$ and low PNI groups $\left(\chi^{2}=4.479, \mathrm{P}=0.034\right)$ was still greater than the number with stage I/II (Table S2).

\section{Discussion}

Nutrition is an important component of patients undergoing surgery. Malnutrition often occurs before the loss 
Table 4 Univariate and Multivariate Analysis of Prognostic Factors for Overall Survival (OS) of Rectal Cancer Patients

\begin{tabular}{|c|c|c|c|c|}
\hline \multirow[t]{2}{*}{ Characteristic } & \multicolumn{2}{|l|}{ Univariate Analysis } & \multicolumn{2}{|c|}{ Multivariate Analysis } \\
\hline & $\begin{array}{l}\text { Hazard Ratio } \\
{[95 \% \mathrm{Cl}]}\end{array}$ & $P$ value & $\begin{array}{l}\text { Hazard Ratio } \\
{[95 \% \mathrm{Cl}]}\end{array}$ & $P$ value \\
\hline $\begin{array}{l}\text { Age } \\
\qquad 60 y \\
>60 y\end{array}$ & $\begin{array}{l}\text { I. } \\
1.267[0.789-2.036]\end{array}$ & 0.327 & & \\
\hline $\begin{array}{c}\text { Gender } \\
\text { Male } \\
\text { Female }\end{array}$ & I $1.061[0.647-1.738]$ & 0.816 & & \\
\hline $\begin{array}{l}\text { Tumor Size } \\
\qquad 5 \mathrm{~cm} \\
>5 \mathrm{~cm}\end{array}$ & I. $156[0.62 \mid-2.154]$ & 0.647 & & \\
\hline $\begin{array}{l}\text { Morphological ty } \\
\text { Elevated } \\
\text { Ulcerated } \\
\text { Infiltrated }\end{array}$ & $\begin{array}{l}\text { I } \\
1.336[0.768-2.323] \\
2.508[1.150-5.472]\end{array}$ & $\begin{array}{l}0.305 \\
0.021\end{array}$ & & \\
\hline $\begin{array}{l}\text { Tumor deposits } \\
\text { Negative } \\
\text { Positive }\end{array}$ & $2.209[1.344-3.631]$ & 0.002 & $\begin{array}{l}\text { I } \\
-\end{array}$ & 0.927 \\
\hline $\begin{array}{l}\text { TNM stage } \\
\text { I/II } \\
\text { III/IV }\end{array}$ & $3.305[1.987-5.495]$ & $<0.000$ I & $2.816[1.662-4.77 \mid]$ & $<0.000$ I \\
\hline $\begin{array}{l}\text { PAB } \\
\quad \leq 170 \mathrm{mg} / \mathrm{L} \\
>170 \mathrm{mg} / \mathrm{L}\end{array}$ & $\begin{array}{l}\text { I } \\
0.532[0.296-0.956]\end{array}$ & 0.035 & $\begin{array}{l}1 \\
-\end{array}$ & 0.353 \\
\hline $\begin{array}{l}\text { PNI } \\
\text { Low } \\
\text { High }\end{array}$ & $\begin{array}{l}\text { I } \\
0.14 \mid[0.07 \mid-0.280]\end{array}$ & $<0.0001$ & $\begin{array}{l}\text { I } \\
0.225[0.111-0.454]\end{array}$ & $<0.000$ I \\
\hline $\begin{array}{l}\text { AGR } \\
\text { Low } \\
\text { High }\end{array}$ & $\begin{array}{l}\text { I } \\
0.591[0.357-0.980]\end{array}$ & 0.042 & $\begin{array}{l}1 \\
-\end{array}$ & 0.366 \\
\hline
\end{tabular}

Notes: P-value $<0.05$ are shown in bold. In colon cancer, the cut off values of PNI and AGR are 48.225 and 1.325 , respectively. In rectal cancer, the cut off values of PNI and AGR are 39.625 and 1.615 , respectively.

Abbreviations: PAB, Prealbumin; PNI, Prognostic nutritional index; AGR, Albumin to globulin ratio; TNM, T, Tumor (Topography), N, Lymph Node, M, Metastasis; OS, overall survival; $\mathrm{Cl}$, confidence interval.

of weight. Therefore, it is necessary to find an efficient index to reflect patients' nutritional status. In our study, we measured various nutritional parameters in patients with colorectal cancer and found that a high PNI, PAB, and AGR predict higher survival times. In addition, multivariate Cox regression analysis showed that of the PNI, PAB and AGR, only the PNI was an independent risk factor for OS in patients with colon and rectal cancer.

Studies have shown that a low PNI can predict poor prognosis in patients with different digestive system malignancies. ${ }^{14-16}$ PNI count is related to the absolute number of serum albumin and peripheral lymphocytes. It is usually used to evaluate the nutritional status of patients and is related to the prognosis of patients. Lymphocytes are white blood cells that are helpful for the body to resist the invasion of tumours and are an important cellular component of the immune response function of the human body. ${ }^{17}$ Lymphocytes can induce apoptosis, inhibit tumour growth, and kill tumour cells through cytotoxicity. ${ }^{18}$ Lymphocytopenia can lead to abnormal immune function, which in turn reduces the body's immunity to tumours. ${ }^{19}$ Lymphocytes connected with tumour 
A

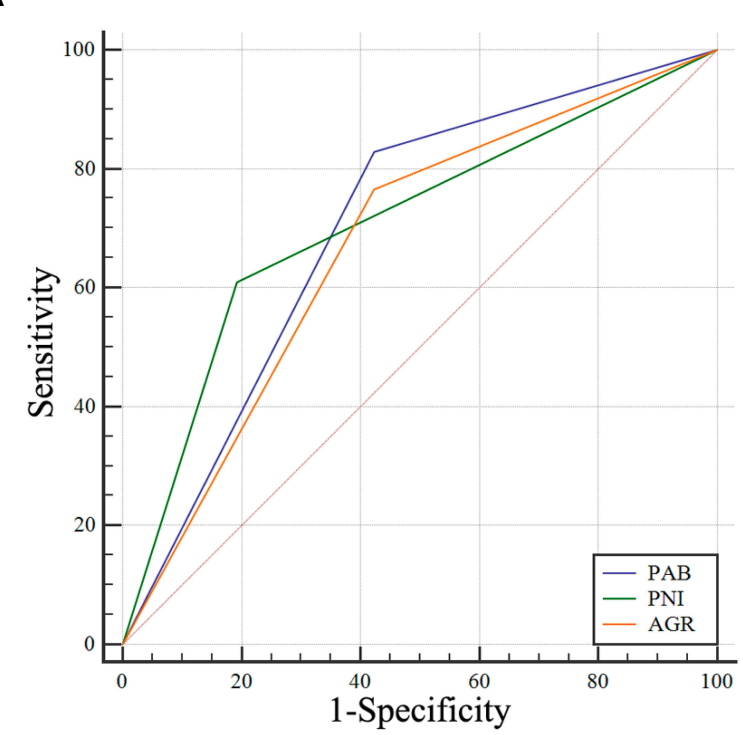

B Rectal Cancer

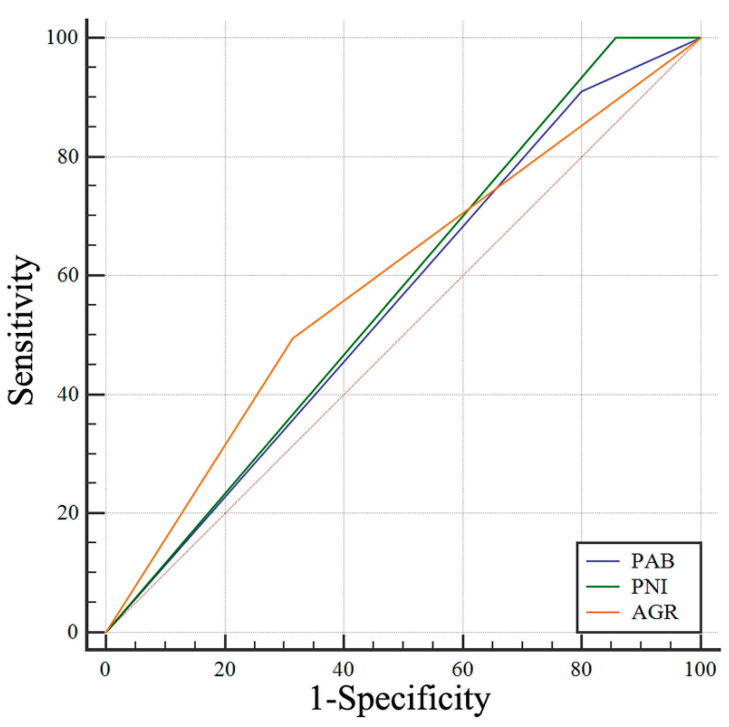

Figure 4 Receiver operating characteristic (ROC) analysis of prealbumin (PAB), prognostic nutritional index (PNI), and albumin and globulin ratio (AGR) in colon and rectal cancer. (A) Colon cancer; (B) Rectal cancer.

infiltrating $\mathrm{T}$ lymphocytes play a key anti-tumour role by initiating the cytotoxic immune response. ${ }^{20}$ Patients with low lymphocyte counts are always in a state of preoperative immunodeficiency. ${ }^{21}$ Therefore, the PNI may reflect the balance between inflammation and the immune response in the tumour microenvironment.

Serum albumin is an alternative biomarker produced by hepatocytes and regulated by inflammatory cytokines, including interleukin- 6 , tumour necrosis factor- $\alpha$ and oxidative stress. ${ }^{22}$ Albumin is an important clinical feature indicating the nutritional status of patients. However, because its half-life is approximately 21 days, it takes 3 months to reach a stable state. $\mathrm{PAB}$ is a tryptophan-rich protein produced by hepatocytes that has a function similar to that of albumin with a half-life of only $2-3$ days. $^{23}$ Therefore, it can reflect the synthesis of protein in the patient's body more quickly and stably. Once the human body is malnourished, the PAB value will decrease within only three days. In recent studies, PAB has been considered an important nutritional indicator of gastric, oesophageal, ovarian and lung cancer in long-term clinical outcomes. ${ }^{24-26}$ In our study, we found that PAB was a prognostic risk factor for patients with colorectal cancer in univariate analysis, but after multivariate adjustment for other variables, PAB was no longer an independent risk factor for patients.

A decrease in the ratio of serum albumin to globulin can easily reflect other diseases, such as oedema, kidney disease and liver disease. Some researchers have pointed out that the AGR is an independent factor in patients with colorectal cancer. ${ }^{27}$ Our study analysed patients with colon cancer and rectal cancer and found that the AGR is an independent risk factor affecting the survival time of patients with colon cancer, but for patients with rectal cancer, the AGR is not an independent risk factor for survival.

Table 5 The Area Under the Curve (AUC) of PAB, PNI and AGR in Patients with Colon and Rectal Cancer

\begin{tabular}{|l|l|l|l|l|l|l|}
\hline \multirow{2}{*}{ Characteristics } & \multicolumn{2}{l|}{ Colon Cancer } & \multicolumn{3}{l|}{ Rectal Cancer } \\
\cline { 2 - 7 } & AUC & $\mathbf{9 5 \%} \mathbf{C l}$ & $\mathbf{P}$ value & Area & $\mathbf{9 5 \%} \mathbf{~ C l}$ & $\mathbf{P}$ value \\
\hline $\mathrm{PAB}$ & 0.703 & {$[0.630-0.768]$} & $<\mathbf{0 . 0 0 0 1}$ & 0.555 & {$[0.479-0.629]$} & 0.209 \\
$\mathrm{PNI}$ & 0.709 & {$[0.636-0.774]$} & $<0.0001$ & 0.571 & {$[0.496-0.645]$} & 0.641 \\
$\mathrm{AGR}$ & 0.671 & {$[0.597-0.739]$} & $<\mathbf{0 . 0 0 0 1}$ & 0.591 & {$[0.515-0.663]$} & $\mathbf{0 . 0 1 7}$ \\
\hline
\end{tabular}

Notes: P-value $<0.05$ are shown in bold. In colon cancer, the cut off values of PNI and AGR are 48.225 and I.325, respectively. In rectal cancer, the cut off values of PNI and AGR are 39.625 and I.6I5, respectively.

Abbreviations: AUC, Area under the curve; $\mathrm{Cl}$, confidence interval; PAB, Prealbumin; PNI, Prognostic nutritional index; AGR, Albumin to globulin ratio. 
When analysing the TNM stage and PAB, PNI, and AGR, the number of patients with colon cancer in the low PNI group was higher than that in the high PNI group; among patients with rectal cancer, the number of patients with stage III/IV disease in the low PAB and low PNI groups was also significantly higher than that in stage I/II disease. As patients with cancer progress to advanced stages, cachexia causes a large amount of nutritional consumption, which is difficult to redress through intravenous nutritional support. This is also an indication of poor prognosis.

There are some limitations that should be acknowledged in our research. First, we only collected the blood indexes before the operation and did not follow up on the changes in blood indexes after the operation in time. Our study did not analyse rectal cancer with different types of surgery (Dixon or Miles). In addition, in our study, approximately $47 \%$ of patients with rectal cancer were stage III/IV because these patients were pathologically confirmed to be stage III/IV. Therefore, there is a need to expand the sample size and conduct a prospective study on all patients.

\section{Conclusions}

In summary, this retrospective study, through univariate Cox regression, showed that patients with low PNI, PAB, and AGR values had poor prognosis regarding colon and rectal cancer, but multivariate Cox regression only showed that the PNI had a good predictive ability in both tumours.

\section{Abbreviations}

PNI, prognostic nutritional index; PAB, Prealbumin; AGR, the albumin to globulin ratio; OS, Overall survival; ROC, Receiver operating characteristic; AUC, area under the curve; TNM, Tumor-node-metastasis.

\section{Ethics Approval and Consent Statement}

This study has been performed in accordance with the Declaration of Helsinki. The research protocol was approved by the First Affiliated Hospital of Anhui Medical University Ethic committee.

\section{Acknowledgment}

Zhengyu Hu and Yan Li are co-first authors for this study.

\section{Author Contributions}

All authors made substantial contributions to conception and design, acquisition of data, or analysis and interpretation of data; took part in drafting the article or revising it critically for important intellectual content; gave final approval of the version to be published; and agree to be accountable for all aspects of the work.

\section{Funding}

This work was supported by the National Science Foundation of China (No.81602425 to Bo Chen).

\section{Disclosure}

The authors declare that they have no competing interests in this work.

\section{References}

1. Li XN, Wang ZJ, Ye CX, Zhao BC, Li ZL, Yang Y. RNA sequencing reveals the expression profiles of circRNA and indicates that circDDX17 acts as a tumor suppressor in colorectal cancer. $J$ Exp Clin Canc Res. 2018;37.

2. Siegel RL, Miller KD, Jemal A. Cancer statistics, 2019. CA Cancer J Clin. 2019;69(1):7-34. doi:10.3322/caac.v69.1

3. Basnet S, Lou QF, Liu N, et al. Tumor deposit is an independent prognostic indicator in patients who underwent radical resection for colorectal cancer. J Cancer. 2018;9(21):3979-3985. doi:10.7150/ jca. 27475

4. Klein-Scory S, Maslova M, Pohl M, et al. Significance of liquid biopsy for monitoring and therapy decision of colorectal cancer. Transl Oncol. 2018;11(2):213-220. doi:10.1016/j.tranon.2017.12.010

5. Kuipers EJ, Grady WM, Lieberman D, et al. Colorectal cancer. Nat Rev Dis Primers. 2015;1.

6. Chen EY, Kardosh A, Nabavizadeh N, Lopez CD. Evolving treatment options and future directions for locally advanced rectal cancer. Clin Colorectal Canc. 2019;18(4):231-237. doi:10.1016/j.clcc.2019.06. 005

7. Tisdale MJ. Cachexia in cancer patients. Nat Rev Cancer. 2002;2 (11):862-871. doi: $10.1038 / \mathrm{nrc} 927$

8. Gordon JN, Green SR, Goggin PM. Cancer cachexia. Qjm-Int J Med. 2005;98(11):779-788. doi:10.1093/qjmed/hci127

9. Onodera T, Goseki N, Kosaki G. Prognostic nutritional index in gastrointestinal surgery of malnourished cancer patients. Nihon Geka Gakkai Zasshi. 1984;85(9):1001-1005.

10. Afaneh C, Gerszberg D, Slattery E, Seres DS, Chabot JA, Kluger MD. Pancreatic cancer surgery and nutrition management: a review of the current literature. Hepatobiliary Surg Nutr. 2015;4 (1):59-71. doi:10.3978/j.issn.2304-3881.2014.08.07

11. Han WX, Chen ZM, Wei ZJ, Xu AM. Preoperative pre-albumin predicts prognosis of patients after gastrectomy for adenocarcinoma of esophagogastric junction. World J Surg Oncol. 2016;14(1):279. doi:10.1186/s12957-016-1035-X

12. Patriarca S, Ferretti S, Zanetti R. TNM Classification of malignant tumours - Eighth edition: which news?. Epidemiol Prev. 2017;41 (2):140-143. doi:10.19191/EP17.2.P140.034

13. Mao W, Liu S, Wang K, et al. Cystatin $\mathrm{C}$ in evaluating renal function in ureteral calculi hydronephrosis in adults. Kidney Blood Press Res. 2019;1-13.

14. Tokunaga R, Sakamoto Y, Nakagawa S, et al. Prognostic nutritional index predicts severe complications, recurrence, and poor prognosis in patients with colorectal cancer undergoing primary tumor resection. Dis Colon Rectum. 2015;58(11):1048-1057. doi:10.1097/ DCR.0000000000000458 
15. Filip B, Scarpa M, Cavallin F, et al. Postoperative outcome after oesophagectomy for cancer: nutritional status is the missing ring in the current prognostic scores. Eur J Surg Oncol. 2015;41(6):787-794. doi:10.1016/j.ejso.2015.02.014

16. Jiang N, Deng JY, Ding XW, et al. Prognostic nutritional index predicts postoperative complications and long-term outcomes of gastric cancer. World J Gastroenterol. 2014;20(30):10537-10544. doi:10.3748/wjg. v20.i30.10537

17. Dunn GP, Old LJ, Schreiber RD. The immunobiology of cancer immunosurveillance and immunoediting. Immunity. 2004;21(2):13 7-148. doi:10.1016/j.immuni.2004.07.017

18. Guo J, Chen S, Chen Y, Li S, Xu D. Combination of CRP and NLR: a better predictor of postoperative survival in patients with gastric cancer. Cancer Manag Res. 2018;10:315-321. doi:10.2147/CMAR

19. Rosenberg SA. Progress in human tumour immunology and immunotherapy. Nature. 2001;411(6835):380-384. doi:10.1038/350 77246

20. Grimm M, Feyen O, Hofmann H, et al. Immunophenotyping of patients with oral squamous cell carcinoma in peripheral blood and associated tumor tissue. Tumour Biol. 2016;37(3):3807-3816. doi:10. 1007/s13277-015-4224-2

21. Chu-Yuan H, Jing $\mathrm{P}$, Yi-Sheng $\mathrm{W}$, et al. The impact of chemotherapy-associated neutrophil/lymphocyte counts on prognosis of adjuvant chemotherapy in colorectal cancer. BMC Cancer. 2013;13:177. doi:10.1186/1471-2407-13-177
22. Hirahara N, Tajima Y, Fujii Y, et al. Preoperative prognostic nutritional index predicts long-term outcome in gastric cancer: a propensity score-matched analysis. Anticancer Res. 2018;38(8):47 35-4746. doi:10.21873/anticanres.12781

23. Chertow GM, Ackert K, Lew NL, Lazarus JM, Lowrie EG. Prealbumin is as important as albumin in the nutritional assessment of hemodialysis patients. Kidney Int. 2000;58(6):2512-2517. doi:10. 1046/j.1523-1755.2000.00435.x

24. Zhou J, Hiki N, Mine S, et al. Role of prealbumin as a powerful and simple index for predicting postoperative complications after gastric cancer surgery. Ann Surg Oncol. 2017;24(2):510-517. doi:10.1245/ s10434-016-5548-x

25. Kelly P, Paulin F, Lamont D, et al. Pre-treatment plasma proteomic markers associated with survival in oesophageal cancer. $\mathrm{Br} J$ Cancer. 2012;106(5):955-961. doi:10.1038/bjc.2012.15

26. Kawai H, Ota $\mathrm{H}$. Low perioperative serum prealbumin predicts early recurrence after curative pulmonary resection for non-small-cell lung cancer. World J Surg. 2012;36(12):2853-2857. doi:10.1007/s00268012-1766-y

27. Hachiya H, Ishizuka M, Takagi K, et al. Clinical significance of the globulin-to-albumin ratio for prediction of postoperative survival in patients with colorectal cancer. Ann Gastroenterol Surg. 2018;2 (6):434-441. doi:10.1002/ags3.12201

\section{Publish your work in this journal}

Cancer Management and Research is an international, peer-reviewed open access journal focusing on cancer research and the optimal use of preventative and integrated treatment interventions to achieve improved outcomes, enhanced survival and quality of life for the cancer patient.
The manuscript management system is completely online and includes a very quick and fair peer-review system, which is all easy to use. Visit http://www.dovepress.com/testimonials.php to read real quotes from published authors. 